\title{
A survey on the effects of parents' involvement on schoolchildren educational background
}

\author{
Mahnaz Hemmati Noedoust Gilani ${ }^{{ }^{*}}$, Sajedeh Sadeghizadeh ${ }^{\mathrm{b}}$, Mohammad Reza Iravani ${ }^{\mathrm{c}}$ and \\ Mohammad Sadeghi Zadeh ${ }^{\mathrm{d}}$
}

\author{
${ }^{a}$ Assistant Professor, Department of Management ( Public Administration), Payame Noor University ,PO BOX 19395-3697, Iran \\ ${ }^{b}$ Ph.D. Research Scholar, Faculty of Social Science, University of Malaya, Malaysia \\ ${ }^{c}$ Assistant Professor, Department of Social Work, Islamic Azad University Khomeinishahr Branch, Daneshjou Blvd, Iran
}

${ }^{d}$ MBA Graduate, Faculty of Management, Multimedia University, Malaysia

AR T I C L E I N F A A S T A T

Article history:

Received December 23, 2011

Received in Revised form

March, 25, 2012

Accepted 27 April 2012

Available online

April 302012

Keywords:

Schoolchildren

Parental involvement

Cooperation

\section{Introduction}

One of the most important ways to improve educations in schools is to increase parents' involvement in different school activities. Parents are able to perform many value-added activities and share their knowledge and experiences with school officials. They are also able to provide necessary suggestions to make valuable changes in not only teaching courses and materials but also they could provide advisory comments in governmental levels. During the past few decades, there have been tremendous efforts to study the effects of parents' involvement on improving different educational programs. Vahedi (2010) performed an investigation on parents' participation in high schools administration and its impact on school activities. He explained that policy makers intuitively accept the importance of parental involvement in schools. School administrators and teachers face different challenges associated with reaching all parents in positive ways, implementing strategies, which

\footnotetext{
* Corresponding author. Tel: +989121979453

E-mail addresses: mahtty41@yahoo.com (M. Hemmati Noedoust Gilani)

\begin{abstract}
Today, there is no doubt that parents can significantly improve educational level by their cooperation in schools. Parents are capable of executing different value-added activities and experiences with school officials. In this survey, we performed an 450 committees out of 150 schools. In each province, we have selected 50 schools in different levels from elementary to high school. In our survey, there were 311 people who non(18ferent committees, 28 were responsible and 25 were from other specialist people. In summary, there were about 1289 participants in this survey. The results of our survey indicate that parents can substantially contribute to schools to increase their capabilities through sharing their knowledge and expertise. However, solve any problem and they mostly disagree to share their duties with parents.
\end{abstract}

(c) 2012 Growing Science Ltd. All rights reserved. 
would yield in improved student achievement. Vahedi in his study considered the students' Parents, administrators and teachers of high schools in Tabriz city (500 high schools) of Iran during the academic year 2007-2008. All gathered data analyzed and the results yielded a statistically significant correlation between parents' participation and decision making, children learning and school activities in reading $(\mathrm{p}<.01)$.

Kim (2009) investigated the barriers in parental involvement and reviewed literature associated with findings on the school barriers, which prevent minority parents' participation in their children's school in the United States. Kim identified different school barriers including: "(a) teachers' perception about the efficacy of minority parents, (b) teachers' perception concerning the capacity of minority parents, (c) teachers' beliefs in the effectiveness of parental involvement and developmental philosophy, (d) teachers' self-efficacy in teaching effectiveness, (e) school friendliness and positive communication, (f) diversity of parental involvement programs, (g) school policies, and (h) school leadership". Kim concluded that increased understanding on the nature of minority parental involvement in their children's school could lead to a more collaborative home-school partnership and ensure the long-term success of parental involvement.

Zingerevich and Patricia D. (2009) investigated the contribution of executive functions to participation in school activities of children with high functioning autism spectrum disorder. The study described the contribution of executive functions to participation in school activities of children diagnosed with ASD ages 6-9 years while controlling for sensory processing. 24 children, ages 73112 months (S.D. = 11.4), diagnosed with high functioning ASD were examined with the Wisconsin Card Sorting Test. Their teachers accomplished the Behavior Rating Inventory of Executive Function and the School Function Assessment questionnaire. Parents also accomplished the Sensory Profile and a demographic questionnaire. They reported that executive functions could contribute to participation in school activities over and above the contribution of sensory processing. More specifically, the abilities to resist impulsive responses, to stop a behavior at the appropriate time, and to regulate emotional responses contributed to participation.

Addi-Raccah and Ainhoren (2009) investigated school governance and teachers' attitudes to parents' involvement in schools. The study examined teachers' attitudes towards parental involvement in schools as a function of four types of school governance. A discriminant analysis determined various profiles of teachers' attitudes towards parental involvement including resistant and negative attitudes characterized schools where parents were empowered. Ambivalent behaviors characterized schools with professional and bureaucratic modes of governance, and positive attitudes were found in schools with partnership governance. This means that the latter mode of governance was a promising step towards a community-oriented approach.

Kohl et al. (2000) studied parent involvement in school conceptualizing multiple dimensions and their relationships with family and demographic risk factors. Measures were gathered from a normative sample of 387 children in kindergarten and first grade from high-risk neighborhoods in 4 different sites. First, a confirmatory factor analysis of a theoretical factor model of PI determined 6 reliable multiple-reporter PI factors including Parent-Teacher Contact, Parent Involvement at School, Quality of Parent-Teacher Relationship, Teacher's Perception of the Parent, Parent Involvement at Home, and Parent Endorsement of School. Next, the relationships among three specific family and demographic risk factors-parental education level, maternal depression, and single-parent statusand these 6 PI factors were investigated based on path analyses in structural equation modeling. The results showed that three risk factors were differentially associated with the 6 PI factors: Parental education was substantially related to 4 PI outcomes, maternal depression was significantly associated with 5 PI outcomes, and single-parent status was substantially related to 3 PI outcomes.

Telem and Pinto (2006) investigated the impact of information technology on school-parents and parents-student interrelations. They explored the influence of a school management information 
system on the relationship between parents and school and parents and their student children based on the children's learning, behavior and attendance (LBA), during one academic year, in a vocational high school, located in a mainstream socio-economic neighborhood. They reported that parents' LBA interrelations with the principal, homeroom teachers, grade level coordinators, and the school as an institution as well as with their children changed noticeably.

Coulton and Irwin (2009) investigated the degree in which parental community involvement and neighborhood safety and disadvantage influenced participation in out-of-school activities. The results showed that children whose parents were involved in community volunteering and action were more likely to take part in out-of-school activities. Neighborhood safety ratings also influenced positively on participation. Cross-level interactions showed that unsafe conditions influenced less if parents volunteered in the community and that participation among African Americans and Hispanics was less inhibited by unsafe conditions than was participation for Whites and other ethnic groups.

Telem (2005) studied the influence of the computerization of a high school's pedagogical administration on homeroom teacher-parents interrelations. Miedel Barnard (2004) examined parent involvement in elementary school and educational attainment. They explained that while educational success in high school could be linked to elementary school achievement, there is little proof that parent involvement in elementary school has provided lasting benefits to children through high school. Using data from the Chicago Longitudinal Study, the study examined the relationship between parent involvement in elementary school and success in high school. The results indicated that even after controlling for background characteristics and risk factors, parent involvement in school was substantially related to lower rates of high school dropout, increased on-time high school completion, and highest grade completed. The study also recommended that parent involvement in school was a necessary component in early childhood education to help promote long-term effects. Recently, Mager and Nowak (2012) reviewed the effects of student participation in decision making at school and covered most of the related literature.

In this paper, we present an empirical study to investigate the effects of parental involvement in schools. The organization of this paper first presents details of our survey in section 2 and the findings of the survey are presented in section 3. Finally, concluding remarks are given in the last section to summarize the contribution of the paper.

\section{The proposed study}

\subsection{Sample size}

The population of this study focuses on three provinces of Tehran, Boushehr and Mazandaran in Iran. We have chosen 450 committees out of 150 schools. In each province, we have selected 50 schools in different levels from elementary to high school. In our survey, there were 311 people who were not members of any committee, 187 were principals, 738 were members of different committees, 28 were responsible and 25 were from other specialist people. In summary, there were about 1289 participants in this survey.

\subsection{Questionnaire}

There were two questionnaires, the first one was associated with members of special committees and the parents who did not belong to any committee. There was another questionnaire, which was distributed among school principals and they were asked about how we could use parents' involvement. One questionnaire was distributed among specialist of parent-teacher associations and they were asked on how to absorb parents for involvement. The last questionnaire was distributed among specialists. 


\subsection{Reliability and validity of instruments}

In order to validate the questionnaire, we chose five people and calculated Cronbach alpha for different questions. We observed that all ratios were almost well above the minimum desirable level of 0.7 .

\section{The results}

In this section, we present details of our survey on four different questions. The first questionnaire was associated with detecting appropriate methods for implementing the skills of non-committee members.

\subsection{The first question of the survey: Agreement on different methods for absorbing people (for non- committee members)}

\subsubsection{Descriptive information}

As we have already explained, the samples were chosen from three provinces and $37 \%, 32.5 \%$ and $30.5 \%$ were from Boshehr, Mazandaran and Tehran provinces, respectively. In terms of educational level, $34.7 \%$ were in elementary schools, $28.9 \%$ were in secondary schools and $32.8 \%$ were attending high schools and 3.5\% did not respond this question. Among the members, $72.7 \%$ were living in cities, $23.2 \%$ were living in rural areas and the remaining $4.2 \%$ did not respond to this question. In our survey, $57.2 \%$ of the school children could walk very easily to school since the distance between home and school was less than one kilometer but $13.2 \%$ needed to use public or private vehicles to go to school. In terms of the number of children, 31.5\% of the participants had only one child, $42.1 \%$ had two children, $13.5 \%$ took care of three schoolchildren and the remaining had more than three children. In our survey, $92.9 \%$ of the participants' children were attending public school and the rest of them were studying at private school. In terms of the time, $66.9 \%$ of the children were attending school during the morning time, $1 \%$ in the afternoon and $29.9 \%$ of them in both.

\subsubsection{Binomial test results on parents who were not members of any committee}

In this section, we have asked the parents who were not members of any committee on whether the methods we used for absorbing people were appropriate or not.

There were six questions and the first question consists of 16 different questions in Likert scale from completely agree to completely disagree. In the first question, we asked people whether we should determine school's requirement first and then ask parents for help, whether we detect parents' skills and then ask for help, whether there is any time vacancy to ask parents to help, etc. The people who were asked on these 16 questions completely agreed on all 16 questions and the result of our binomial test were completely confirmed with P-value $=0.000$.

In the second question of the survey, we asked them to name different appropriate methods for increasing parents' cooperation in school and they provided a set of totally different ideas such as creating website on gathering parental help, introducing special parents in committee to encourage other parents to help more, setting up a library, etc.

In the third question of the survey, we asked parents on how we can increase people's interest on contributing more. There were nine questions in this part including having an appropriate plan, increasing parents' authorities, preparing a document on necessity of cooperation of parents, legalizing parents' cooperation, parents' partnership in events, assigning an appropriate budget for the work, continuous performance measurement, having specified education program for parents and providing a report on decisions made. The result of our binomial test were completely confirmed with P-value $=0.000$. 
In the fourth question of the survey, we asked the audience on the degree on each activity parents could perform to increase their enrolment. There were 30 questions in this part and we asked the participants on different questions such as detecting skilful parents and ask them to cooperate, detecting appropriate facilities in school and using them in school, asking parents to teach in outside classes, detecting those parents who could financially help repair sport facilities, etc. The result of our binomial test were completely confirmed with P-value $=0.000$.

In the fifth question, we asked the participants about different barriers on absorbing parents' cooperation. There were 12 questions associated with this part of the survey. Paying no attention to parents' skills, having no information on parents' skills, parents' low culture are among these questions asked the survey people in Likert scale and the result of our binomial test were completely confirmed with P-value $=0.000$.

In the sixth question, we asked them to mention how we can improve parents' involvement and remove any possible barriers. The participants suggested various methods including having an appropriate plan for parents' involvement, encouraging those parents' who are more interested in such programs, etc.

\subsection{The second question of the survey: Agreement on different methods for absorbing people (for principals)}

\subsubsection{Descriptive information}

As we have already explained, the samples were chosen from three provinces and $41.2 \%, 31.6 \%$ and 27.3\% were from Boshehr, Mazandaran and Tehran provinces, respectively. $46.5 \%$ of the survey people were female, $51.3 \%$ were male and $2.1 \%$ did not specify in questionnaire. In terms of educational level, 30.5\% were in elementary schools, 39.0\% were in guided schools and $25.1 \%$ were attending high schools and 5.2\% did not respond this question. Among the members, 62.0\% were living in cities, $14.4 \%$ were living in rural areas and the remaining $23.5 \%$ did not respond to this question. In our survey, $88.1 \%$ of the participants' children were attending public school and the rest of them were studying either at private school or did not mention. In terms of their educational level, $1.6 \%$ had less than 12 years of education, 3.2\% finished high school, 10.2\% had two years of college studies, $73.3 \%$ maintained bachelor degree, 9.6\% had master or higher level of education and 2.1\% did not mention anything on their educational background. In terms of their work experiences, $4.3 \%$ of the participants had less than 5 years of job experience, $7.5 \%$ had up to 10 years of job experience, $13.4 \%$ had up to 15 years of job experience, $22.5 \%$ had between 15 to 20 years, $39.6 \%$ had more than 20 years and $12.8 \%$ did not mention about their job experiences. In terms of the time, $65.8 \%$ of the children were attending school during the morning time, $2.1 \%$ in the afternoon, $27.3 \%$ of them in both and $4.8 \%$ of the participants did not respond to this question.

\subsubsection{Binomial test results on parents who were acting as principals of schools}

There were 10 questions associated with this part of the survey and most of them were in Likert scale from completely agree to completely disagree. In the first question, we asked people whether we should determine school's requirement first and then ask parents for help, whether we detect parents' skills and then ask for help, whether there is any time vacancy to ask parents to help, etc. The people who were asked on these 16 questions completely agreed on all 16 questions and the result of our binomial test were completely confirmed with P-value $=0.000$.

In the second question of the survey, we asked them to name different appropriate methods for increasing parents' cooperation in school and they provided a set of totally different ideas such as detecting effectiveness parents' suggestions, using media for more cooperation, absorbing people with special skills to help, etc. 
In the third question of the survey, we asked parents on how we can increase people's interest on contributing more. There were nine questions in this part including having an appropriate plan, increasing parents' authorities, preparing a document on necessity of cooperation of parents, legalizing parents' cooperation, parents' partnership in events, assigning an appropriate budget for the work, continuous performance measurement, having specified education program for parents and providing a report on decisions made. The result of our binomial test were completely confirmed with P-value $=0.000$.

We also asked participants about different plans on improving people's enrolment, different activities such as detecting rich people to get more fund for repairing school, etc. and in summary participants believed it is quite possible to use a set of appropriate rules on increasing people's involvement.

3.3. The third question of the survey: Agreement on different methods for absorbing people (for societies)

\subsubsection{Descriptive information}

As we have already explained, the samples were chosen from three provinces and $33.1 \%$, $34.0 \%$ and $32.9 \%$ were from Boshehr, Mazandaran and Tehran provinces, respectively. $50.9 \%$ of the survey people were female, $47.4 \%$ were male and $1.6 \%$ did not specify in questionnaire. In terms of educational level, 31.0\% were in elementary schools, 32.0\% were in secondary schools and 33.2\% were attending high schools and 3.8\% did not respond this question. Among the members, 78.5\% were living in cities, $15.3 \%$ were living in rural areas and the remaining $6.2 \%$ did not respond to this question. In our survey, $50.7 \%$ of the school children could walk very easily to school since the distance between home and school was less than one kilometer, $17.9 \%$ of them needed to walk up to 2 kilometers, $9.5 \%$ had to walk up to 3 kilometers, but $12.9 \%$ needed to use public or private vehicles to go to school. In terms of the number of years they cooperated with school, $48.1 \%$ of the participants had less than 2 years of cooperation, 25.5\% had up to 5 years of job experience, $6.4 \%$ had between 5 to 10 years of related job experience and the rest of them had more than 10 years of cooperation.

In terms of their educational level, $21.7 \%$ had less than 12 years of education, 34.8\% finished high school, $12.3 \%$ had two years of college studies, $23.7 \%$ maintained bachelor degree, 3.8\% had master or higher level of education and $3.7 \%$ did not mention anything on their educational background. In terms of the number of children, $36.6 \%$ of the participants had only one child, $36.6 \%$ had two children, 9.9\% took care of three schoolchildren and the remaining had more than three children. In terms of the time, $62.2 \%$ of the children were attending school during the morning time, $0.7 \%$ in the afternoon, $30.4 \%$ of them in both and $6.8 \%$ of the participants did not respond to this question. Finally, we asked the participants on the number of hours they participated in the survey and according to our survey results, 21.8\% cooperated up to 5 hours, 6.9\% between 6 to 10 hours, 5\% between 11 to 20 hours, 1.6\% between 21 to 40, 0.8 between 41 to 100, 0.9 more than 100 hours per month. Note that $62.9 \%$ of the participants did not provide any response for this question.

\subsubsection{Binomial test results on parents who were acting as principals of schools}

There were 10 questions associated with this part of the survey and most of them were in Likert scale from completely agree to completely disagree. In the first question, we asked people whether we should determine school's requirement first and then ask parents for help, whether we detect parents' skills and then ask for help, whether there is any time vacancy to ask parents to help, etc. The people who were asked on these 16 questions completely agreed on all 16 questions and the result of our binomial test were completely confirmed with P-value $=0.000$.

3.4. The fourth question of the survey: Agreement on different methods for absorbing people (for specialists) 


\subsubsection{Descriptive information}

As we have already explained, the samples were chosen from three provinces and $32.1 \%, 32.1 \%$ and 32.1\% were from Boshehr, Mazandaran and Tehran provinces, respectively. $25.0 \%$ of the survey people were female, $67.9 \%$ were male and $7.1 \%$ did not specify in questionnaire. In terms of their educational level, 64.3\% maintained bachelor degree, 28.6\% maintained masters degree of science or higher degrees. and $7.1 \%$ did not respond this question. In terms of the number of years they cooperated with school, 3.6\% of the participants had less than 1 years of cooperation, $10.7 \%$ had up to 3 years of job experience, 3.6\% had between 11 to 15 years of related job experience, 32.1\% had between 16 to 20 years of job experience, and $42.9 \%$ had more than 30 years of job experiences.

\subsubsection{Binomial test results on parents who were acting as principals of schools}

There were 7 questions associated with this part of the survey and most of them were in Likert scale from completely agree to completely disagree. In the first question, we asked people whether we should determine school's requirement first and then ask parents for help, whether we detect parents' skills and then ask for help, whether there is any time vacancy to ask parents to help, etc. In summary, we can conclude that the people who participated in our survey were relatively expert in this area and their insight could significantly contribute to our survey. They strongly believed that school officials do not take into account parents' capabilities and do not use their skills on improving educations. In their opinions, school officials even do not believe that the presence of parents at school could help them resolve many issues. The other issue is that many parents are not familiar with their responsibilities against their children.

\section{Conclusion}

In this survey, we have performed an empirical survey in three provinces of Iran from economically rich to poor. We have chosen 450 committees out of 150 schools, where in each province, we selected 50 schools in different levels from elementary to high school. In our survey, there were 311 people who non-committee, 187 were principals, 738 were members of different committees, 28 were responsible and 25 were from other specialist people. In summary, there were about 1289 participants in this survey. The results of our survey indicate that parents can substantially contribute to schools to increase their capabilities through sharing their knowledge and expertise. However, according to experts, school officials do not strongly believe that the presence of parents can solve any problem and they mostly disagree to share their duties with parents. The other issue is that many parents are not familiar with their responsibilities against their children. In summary, we can conclude that parents can significantly contribute to schoolchildren once there is a good regulation, discipline program and more specifically a good support on behalf of principles.

\section{References}

Addi-Raccah, A., \& Ainhoren, R. (2009). School governance and teachers' attitudes to parents' involvement in schools. Teaching and Teacher Education, 25(6), 805-813.

Coulton, C., \& Irwin, M. (2009). Parental and community level correlates of participation in out-ofschool activities among children living in low income neighborhoods. Children and Youth Services Review, 31(3), 300-308.

Kohl, G.O., Lengua, L.J., McMahon, R.J., Conduct Problems Prevention Research Group. (2000). Parent involvement in school conceptualizing multiple dimensions and their relations with family and demographic risk factors. Journal of School Psychology, 38(6), 501-523.

Kim, Y. (2009). Minority parental involvement and school barriers: Moving the focus away from deficiencies of parents. Educational Research Review, 4(2), 80-102.

Mager, U., \& Nowak, P. (2012). Effects of student participation in decision making at school. A systematic review and synthesis of empirical. Educational Research Review, 7(1), 38-61 
Miedel Barnard, W.(2004). Parent involvement in elementary school and educational attainment. Children and Youth Services Review, 26(1), 39-62.

Telem, M. (2005).The impact of the computerization of a high school's pedagogical administration on homeroom teacher-parents interrelations: A case study. Teaching and Teacher Education, 21(6), 661-678.

Telem, M., \& Pinto, S. (2006). Information technology's impact on school-parents and parentsstudent interrelations: a case study. Computers \& Education, 47(3), 260-279.

Vahedi, M.(2010). A study of parents' participation in the high schools administration and its effect on school activities. Procedia - Social and Behavioral Sciences, 2(2), 359-363.

Zingerevich, C., \& Patricia D., L. (2009). The contribution of executive functions to participation in school activities of children with high functioning autism spectrum disorder. Research in Autism Spectrum Disorders, 3(2), 429-437. 